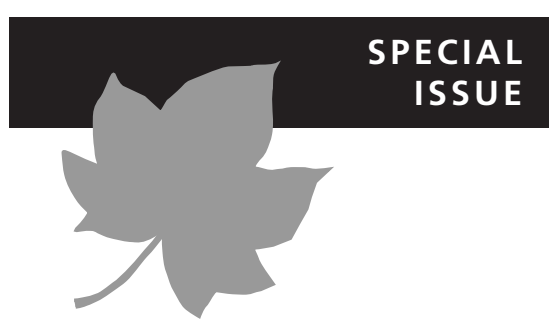

\title{
Drivers of diversity in Macaronesian spiders and the role of species extinctions
}

\author{
Pedro Cardoso ${ }^{1,2 *}$, Miquel A. Arnedo ${ }^{3}$, Kostas A. Triantis ${ }^{1,4}$ and \\ Paulo A. V. Borges ${ }^{1}$
}

${ }^{1}$ Azorean Biodiversity Group (CITA-A),

Departamento de Ciências Agrárias,

Universidade dos Açores, Terra-Chã, 9701-851

Angra do Heroísmo, Portugal, ${ }^{2}$ Smithsonian

Institution, National Museum of Natural

History, 10th \& Constitution NW, MRC 105,

Room E-509, Washington, DC 20560-0105,

USA, ${ }^{3}$ Biodiversity Research Institute \&

Department of Animal Biology, Universitat de Barcelona, Av. Diagonal 645, 08028 Barcelona, Spain, ${ }^{4}$ Biodiversity Research Group, Oxford

University Centre for the Environment, South Parks Road, Oxford OX1 3QY, UK

${ }^{*}$ Correspondence: Pedro Cardoso, Smithsonian Institution, National Museum of Natural History, PO Box 37012, MRC 105, Room E-509, Washington, DC 20013-7012, USA.

E-mail: pcardoso@ennor.org

\section{ABSTRACT}

Aim To identify the biogeographical factors underlying spider species richness in the Macaronesian region and assess the importance of species extinctions in shaping the current diversity.

Location The European archipelagos of Macaronesia with an emphasis on the Azores and Canary Islands.

Methods Seven variables were tested as predictors of single-island endemics (SIE), archipelago endemics and indigenous spider species richness in the Azores, Canary Islands and Macaronesia as a whole: island area; geological age; maximum elevation; distance from mainland; distance from the closest island; distance from an older island; and natural forest area remaining per island - a measure of deforestation (the latter only in the Azores). Different mathematical formulations of the general dynamic model of oceanic island biogeography (GDM) were also tested.

Results Island area and the proportion of remaining natural forest were the best predictors of species richness in the Azores. In the Canary Islands, area alone did not explain the richness of spiders. However, a hump-shaped relationship between richness and time was apparent in these islands. The island richness in Macaronesia was correlated with island area, geological age, maximum elevation and distance to mainland.

Main conclusions In Macaronesia as a whole, area, island age, the large distance that separates the Azores from the mainland, and the recent disappearance of native habitats with subsequent unrecorded extinctions seem to be the most probable explanations for the current observed richness. In the Canary Islands, the GDM model is strongly supported by many genera that radiated early, reached a peak at intermediate island ages, and have gone extinct on older, eroded islands. In the Azores, the unrecorded extinctions of many species in the oldest, most disturbed islands seem to be one of the main drivers of the current richness patterns. Spiders, the most important terrestrial predators on these islands, may be acting as early indicators for the future disappearance of other insular taxa.

\section{Keywords}

Araneae, Azores, Canary Islands, deforestation, habitat loss, indicator taxa, island age, Madeira, Selvagens, species-area relationship.

\section{INTRODUCTION}

It is widely recognized that oceanic islands are natural laboratories for testing ecological, biogeographical and evolutionary theories (Gillespie \& Roderick, 2002; Whittaker \& Fernández-Palacios, 2007). Oceanic islands often are relatively small in size, have distinct boundaries, and usually have low species richness and low higher taxa or clade diversity (although there are exceptions, e.g. plate-margin islands). All these characteristics facilitate the study of biodiversity patterns on islands, freeing them from the confounding factors that are typical of continental datasets (Losos \& Ricklefs, 2009). 
Archipelagos formed by islands of different ages act as snapshots of the evolutionary process and provide insights into the stages of community assembly (e.g. Emerson \& Gillespie, 2008). In addition, in many isolated island archipelagos, substantial speciation has occurred in association with moderate-to-high levels of habitat diversity (Gillespie \& Roderick, 2002; Losos \& Ricklefs, 2009).

The species richness of most organisms changes along several environmental gradients, such as maximum elevation, disturbance, productivity, climate and area. MacArthur \& Wilson's $(1963,1967)$ theory of island biogeography introduced area and isolation as the two main factors determining the species richness of islands without dismissing the importance of habitat diversity and time (see also Wilson, 1969). In their classical formulation, island area and isolation both contribute to an equilibrium species number that is characteristic of each island. Area, although not sufficient for describing species richness patterns in many cases, is one of the most powerful explanatory variables in ecology and biogeography, and also has a wide application in conservation biology (see Rosenzweig, 1995; Whittaker \& Fernández-Palacios, 2007; Triantis et al., 2008a).

Isolation from any possible sources of immigration is recognized as a second important diversity driver. Such sources may be the mainland or other islands, even if they belong to different archipelagos. In fact, the progression-rule pattern (Funk \& Wagner, 1995) states that taxa often occupy newly formed islands by dispersal from an older island in the same archipelago, eventually speciating in the newly colonized territory. This was supported for spider genera such as Tetragnatha (Gillespie, 2004) and Orsonwells (Hormiga et al., 2003) in Hawaii, and for Dysdera (Arnedo et al., 2001) in the Canary Islands. However, species may, at least sometimes, also disperse from younger to older islands, even when these islands are occupied by close relatives (e.g. Juan et al., 2000).

The species-energy theory (Wright, 1983) introduced climatic variables as a further possible explanation for species richness numbers on islands. This rationale was followed by Kalmar \& Currie (2006) and Kreft et al. (2008), who used mean annual temperature and total annual precipitation as two climatic variables that influence the richness of island birds and plants, respectively, at a worldwide scale (but see Whittaker, 2006). On small spatial scales such as islands and archipelagos, however, the islands of specific island groups exhibit more or less the same climatic characteristics, so an effect of temperature or precipitation is usually not observed. Most climatic variability on islands and archipelagos is therefore driven by local elevation variation, which is a surrogate for both climatic variability and niche availability.

A fourth diversity driver is niche availability. This driver is difficult, if not impossible, to measure. Thus, both habitat diversity and maximum elevation have been used as surrogates. Studying the Galapagos snails, Parent \& Crespi (2006) found that habitat diversity, measured as the number of plant species, not island area per se, better predicts the number of speciation events. Kalmar \& Currie (2006) and Kreft et al.
(2008), among others, have also used maximum elevation as a surrogate for habitat diversity and hence niche availability (but see Triantis et al., 2008b). Area and elevation together were also found to be the best predictors of species richness of Hawaiian insects (Peck et al., 1999), with the reasoning that area and elevation are both surrogates for habitat diversity and the opportunities presented for geographical and ecological isolation.

One additional factor already found to have a major influence on the species richness of islands is their geological age (Peck \& Kukalova-Peck, 1990; Borges \& Brown, 1999). Older islands often have more species due to two factors: (1) there is more time for species to immigrate (usually reflected in non-endemic native species richness), and (2) there is more time for speciation (usually reflected in neo-endemic species richness). However, oceanic islands such as those in Macaronesia often have a 'life cycle' with a hump-shaped relationship between area and elevational range and age (Whittaker et al., 2008,2010 ). This is due to the loss of area and topographical complexity of the older islands as subsidence and erosion take their toll (Price \& Clague, 2002; Whittaker et al., 2008, 2010; see figure 3 in Whittaker et al., 2008). The consideration of island age and a possible hump-shaped relationship between age and diversity was the basis for the recently proposed 'general dynamic model of oceanic island biogeography' (hereafter GDM) by Whittaker et al. (2008, 2010; see also Borges \& Hortal, 2009; Fattorini, 2009). Although the different formulations of the model failed to predict the diversification pattern of several arthropod groups in the Azores, the GDM provides an interesting framework to test further hypotheses on island species diversification (Borges \& Hortal, 2009).

The Macaronesian biogeographical region has long been noted for its floral and faunal diversity, and is included in the Mediterranean biodiversity hotspot as one of the most important areas for conservation worldwide (Myers et al., 2000). Macaronesia encompasses the oceanic archipelagos of the Azores, Madeira, Selvagens, the Canary Islands and Cape Verde. The Macaronesian islands share many characteristics, although Cape Verde, which is located much farther south in the Atlantic, is quite distinct in terms of its climate and biota. The major habitat types of Macaronesia are similar between archipelagos, with the dominant typical forest type referred to as laurisilva. Moreover, Europe and the Mediterranean region serve as a source of colonization, with immigrants coming mainly from the Iberian Peninsula and north-western Africa. Macaronesia can therefore be seen as a large biogeographical unit subdivided into smaller subunits, the archipelagos. Cape Verde may, however, be an exception to these rules, presenting a rather distinct set of biotopes and faunal affinities. While true for all the islands, the Azores have particularly high levels of deforestation and native habitat disappearance, with only $2 \%$ of the area being occupied by the primary laurisilva forest that almost completely covered the islands before human occupation (Gaspar et al., 2008). Such rates of deforestation, which started in the 15th century and continued until recently, may have caused numerous unrecorded species extinctions and 
subsequent changes in the species-area relationships on the islands. As the main terrestrial predators on these islands, spiders may have been one of the taxa most affected by deforestation (Cardoso et al., 2007).

Spiders (order Araneae) are one of the most diverse and abundant arthropod orders. They include more than 40,000 known species (Platnick, 2009) and are among the most abundant arthropods in all kinds of habitat in every terrestrial biome. Their relative abundance compared with other arthropod orders is particularly noteworthy in Macaronesia (Borges \& Brown, 2004; Cardoso et al., 2007, 2009; Gaspar et al., 2008). The known richness of the different archipelagos and islands varies widely. The Azores, for example, are very species-poor, with only 39 species considered as native or endemic to the entire archipelago out of a total 122 species recorded (Borges \& Wunderlich, 2005, 2008). Madeira has only 126 indigenous species out of 186 (Cardoso \& Crespo, 2008), while the Canary Islands have 420 indigenous species out of 467 recorded (Oromí et al., 2004). These are relatively low numbers when compared with almost 200 species found in a single hectare of forest on the Portuguese mainland at similar latitudes, with a prediction of over 300 species for a complete assessment during an entire year at each single-hectare location (Cardoso et al., 2008 b,c). This apparently low richness on the islands is largely compensated for by very high levels of endemism, with $79 \%$ of all indigenous species being endemic to Macaronesia.

Given the importance of the Macaronesian region for global conservation efforts and the high proportion of spider species found only there, it is important to understand why the different islands present such disparate richness numbers for their endemic and indigenous (i.e. endemic plus native) spider species. The aim of this work is to study the factors shaping spider species richness and patterns of endemism in the Macaronesian archipelagos (excluding Cape Verde), including the role of native habitat disappearance in the extinction of indigenous species. Our main hypotheses here are that: (1) the richness of Macaronesia as a whole would be related to distance, with the isolation of the Azores contributing to its low species numbers; (2) with a wide range of island ages, the Canary Islands would present a hump-shaped relationship between richness and a combination of area and age, with older islands harbouring fewer species than expected by area alone, due to strong and long-lasting erosion causing low habitat diversity and a much simplified topography of these islands; (3) due to its recent history, the Azorean islands would present a positive relationship between richness and both area and island age (Borges \& Hortal, 2009); and (4) the native habitat area remaining in the Azorean islands could be an additional important diversity driver for the archipelago.

\section{MATERIALS AND METHODS}

\section{Study region}

Volcanic in origin, the Macaronesian islands (excluding the Cape Verde archipelago) are situated in the North Atlantic

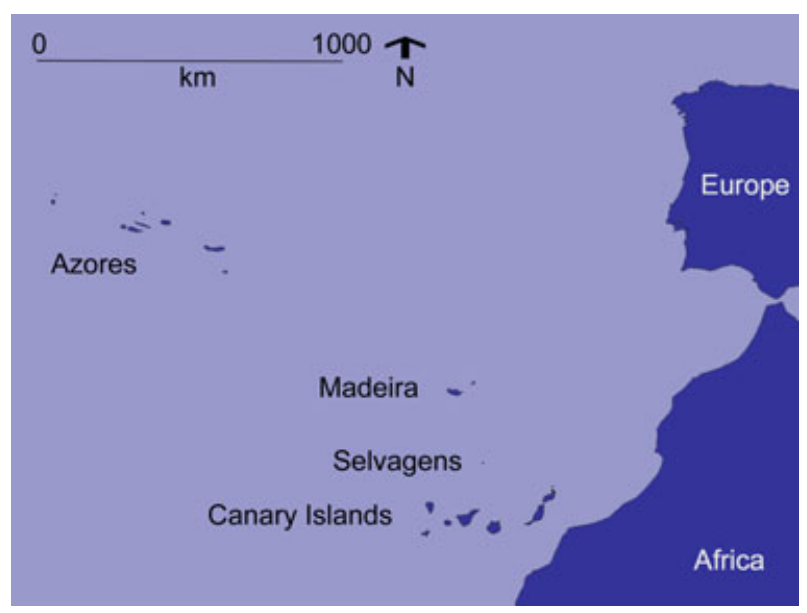

Figure 1 Location of the Macaronesian archipelagos considered in this study.

$\left(27-40^{\circ} \mathrm{N} ; 13-31^{\circ} \mathrm{W}\right)$ with a general north-west-south-east orientation (Fig. 1). The distance of the islands from the mainland, either the Iberian Peninsula or Morocco, varies between $95 \mathrm{~km}$ (Fuerteventura in the Canary Islands) and $1864 \mathrm{~km}$ (Flores in the Azores). The age of the islands ranges from 0.25 Myr old (Pico in the Azores) to $20 \mathrm{Myr}$ old (Fuerteventura in the Canary Islands). In general, the Azorean islands are younger than the rest of the archipelagos in Macaronesia and are much more isolated from the mainland (Table 1). Excluding a number of small islets, data for which are often clumped with data from the closest larger island, the area and elevation of islands in Macaronesia vary respectively from $3 \mathrm{~km}^{2}$ and $147 \mathrm{~m}$ for Selvagem Grande in Selvagens to $2058 \mathrm{~km}^{2}$ and $3711 \mathrm{~m}$ for Tenerife in the Canary Islands. The range of possible explanatory variables is therefore very large, ranging from young, high-elevation islands where it is still possible to witness volcanic eruptions (e.g. Faial, although some old islands such as Lanzarote may experience posterosional volcanism; Carracedo et al., 2003) to very old and eroded islands close to naturally vanishing into the ocean (e.g. Selvagens, but see Geldmacher et al., 2001).

\section{Species data}

We consider the current knowledge of spider diversity in Macaronesia as reasonably complete, although new species are added and described with some regularity. Cape Verde, again, constitutes an exception. These islands have been poorly sampled so far, with species numbers per island ranging from one to 41 known species. Therefore Cape Verde was not considered in our analyses, although this archipelago is generally considered as part of the Macaronesian biogeographical region. As the origin of the fauna of Cape Verde, predominantly from Western Africa, is different from the mainly European and Mediterranean origin of the other archipelagos' fauna, not including this archipelago in the analyses seems justified. 


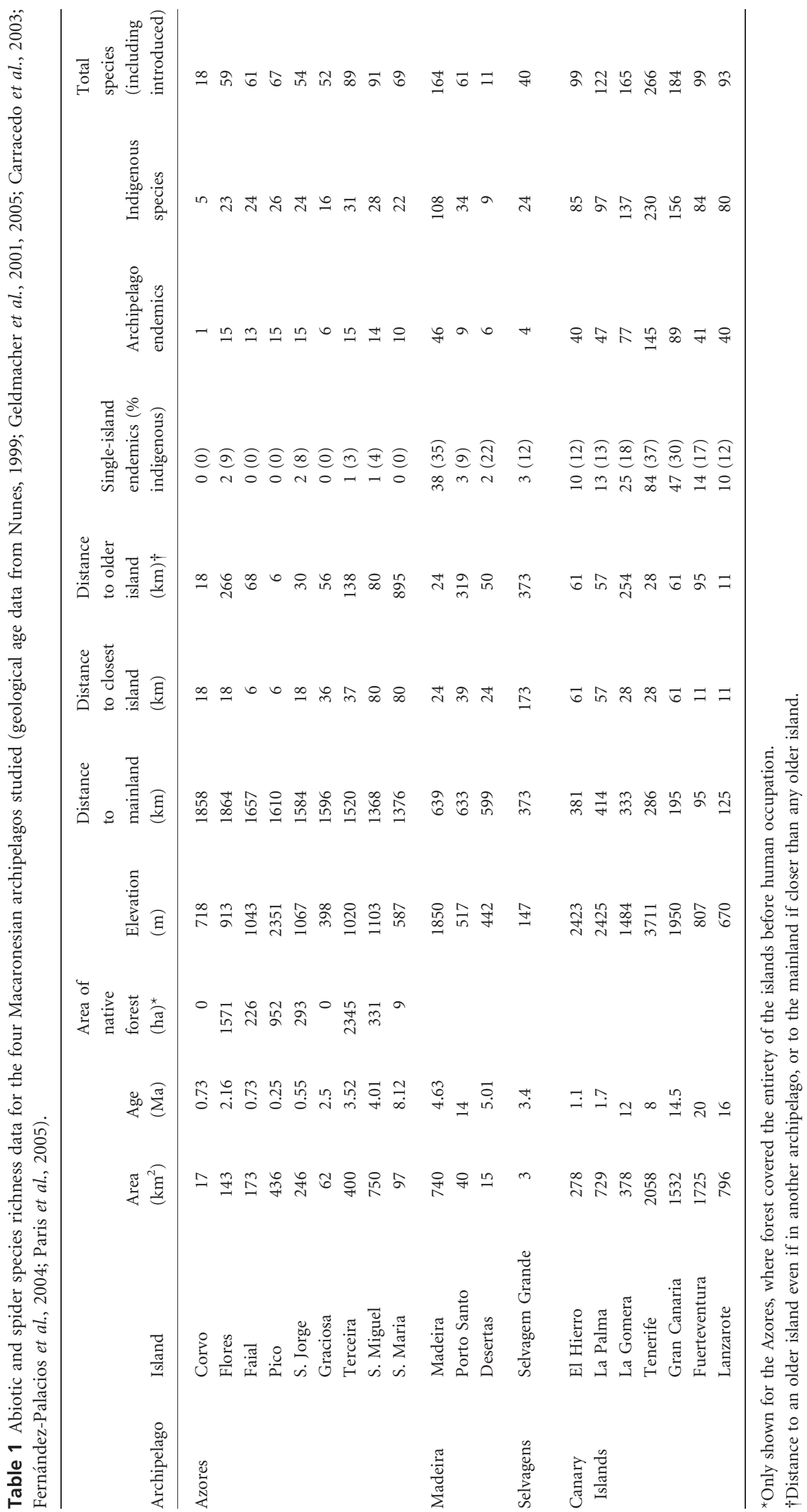


All spider species data used were based on the recently published checklists for the archipelagos (Oromí et al., 2004; Borges \& Wunderlich, 2005; Cardoso \& Crespo, 2008). These lists were updated with recently published material that describes and adds new species for the Azores (Borges \& Wunderlich, 2008) and Madeira (Crespo et al., 2009a, b). All species names were then checked against currently accepted nomenclature (Platnick, 2009), guaranteeing the uniformity of taxon names across all the archipelagos, and avoiding species inflation due to different nomenclatures used in the past within the four archipelagos studied.

We classified all species according to their currently known distribution as single-island endemics (SIEs, species endemic to only one island), archipelago endemics (species endemic to a particular archipelago, including SIEs) and indigenous species (all native species, including both categories of endemic). Although also classified, introduced species (those that can be related to human habitats and that presumably reached the islands due to human activities) were not included in the analyses.

\section{Statistical analysis}

All analyses were conducted for Macaronesia as a whole and repeated individually for the two larger archipelagos, the Azores and the Canary Islands. As mentioned, the islands of these two archipelagos have very different characteristics. Seven variables were chosen as possible predictors of SIE, archipelago endemic and indigenous species richness (Table 1): (1) island area, (2) maximum geological age, (3) maximum elevation, (4) distance to mainland, (5) distance to closest island, (6) distance to closest older island, and (7) natural forest area remaining per island (the latter only for the Azores).

For age of the island, we used the maximum age of the islands except for Selvagem Grande. This island has undergone three eruptive cycles at 24-26, 8-12 and 3.4 Ma (Geldmacher et al., 2001). It is well documented that during the volcanic quiescence following the first phase, the island was below sea level. For the second hiatus, the data are less clear. However, molecular clock estimates for the time of colonization of Selvagem Grande by Dysdera nesiotes are congruent with a reemergence of the island after the third and last eruptive phase (3.4 Ma) (Macías-Hernández et al., 2008). Therefore we used 3.4 $\mathrm{Ma}$ as the time when the island was available for colonization, mainly from the Canary Islands.

The Azores experienced the most severe native habitat destruction of all Macaronesian archipelagos, with islands currently presenting anywhere from no remaining natural forest cover (Corvo and Graciosa) to a maximum of $11 \%$ reached on Flores, although the largest areas are found on Terceira (Table 1). The other islands present intermediate but invariably low extensions of natural forest cover. Santa Maria, the oldest island, presents only 9 ha of native but extremely disturbed forest (all forest cover data from Gaspar et al., 2008). In contrast to the other Macaronesian archipelagos, the
Azorean Islands were also the only islands estimated to be almost entirely covered by forest prior to recent human occupation (Martins, 1993; Silveira, 2007). Therefore they served as a model to test the role of deforestation and subsequent hypothesized species extinctions in shaping the current spider species richness patterns.

The logarithms of predictors were subjected to univariate regression against richness of SIEs, archipelago endemic species and indigenous species in the Azores, the Canary Islands and Macaronesia as a whole. We tested both the semi$\log$ and the log-log models for all relationships. The semi-log model was generally better for the Azores and the Canary Islands, and the log-log model was generally better for Macaronesia. We present only the better-fitting models for each region. The transformation of explanatory variables was undertaken to approximate their distribution to normality. This was assessed only through visual confirmation as the number of islands was invariably low. The only exception was age, which was tested without a logarithmic transformation.

We then tested the same datasets for the different mathematical formulations arising from the GDM (Whittaker et al., 2008, 2010), a model that explicitly incorporates the geological history of islands, in a number of variants. First, with area and age of the islands, we used the AT model [log (area) + time] assuming a linear relationship between time and richness. Then, with area, age of the islands and the square of the age, we used the $\mathrm{ATT}^{2}$ model $\left[\log (\right.$ area $)+$ time - time $\left.^{2}\right]$. Finally, we used a model without any reference to the area of the islands, the $\mathrm{TT}^{2}$ model (time - time ${ }^{2}$ ).

For the Azores, we tested the explanatory power of using the natural forest area per island $(\mathrm{N})$ instead of the entire area of the island (A). This measure was also combined with time and incorporated in the NT and $\mathrm{NTT}^{2}$ models. A final model was tested for this archipelago by combining island area (A) and the proportion of it occupied by natural forest $(\mathrm{pN})$, resulting in the $\mathrm{A}+\mathrm{pN}$ model.

The statistical significance of every model was set to the 0.05 level. Although suggestions have been made in the past statistically to correct this $P$ value when different hypotheses are tested with the same dataset, we disagree with such claims. The Bonferroni correction, or any other similar correction, has been misused a number of times in ecological literature (Moran, 2003; García, 2004). In this particular case, regressions were made independently of each other and evaluated individually, 0.05 being the correct significance level for each one of them. It would be necessary to correct this value only if the objective was to find if any of the 40 performed regressions was significant. As they were evaluated individually, this was not the case.

We have opted also to highlight all regressions with an $r^{2}$ above 0.5 to ensure that trends unconfirmed by statistical significance due to the small number of cases would not be missed. All models were then compared through both the adjusted $r^{2}$ values and Akaike's information criterion (AIC). Both values allowed the comparison of models with a different complexity by penalising models with a higher number of 
parameters, although the AIC was more penalising. The models with the lowest AIC were more parsimonious and therefore preferred, as lower AIC values are attributed to models that are simultaneously most informative (higher $r^{2}$ ) and less complex (lower number of explanatory variables).

\section{RESULTS}

In total, we listed 255 SIEs, 370 archipelago endemic species, and 584 species indigenous to Macaronesia (Table 1). The number of species belonging to each group (SIE, archipelago endemic or indigenous) was very different between islands, the poorest being in the Azores (particularly Corvo with 0, 1 and 5, respectively) and the richest in the Canary Islands (especially Tenerife with 84, 145 and 230, respectively). The percentage of SIEs was also much lower in the Azorean Islands (0-9\% of the indigenous fauna) than in the other archipelagos (9-37\%), including the minute Selvagem Grande (12\%).

Area alone was, in general, a good predictor in the univariate analyses (Fig. 2; Tables 2-4) with significant regressions in almost every combination. The exception was in the Canary Islands, where there was no significant relationship or trend of any sort with area alone (as defined by $r^{2}>0.5$ ). In this archipelago, however, there was a hump-shaped relationship between species richness and time, although it was not significant (Fig. 2; Table 3). There was an increase in the number of species with age followed by a decrease in richness for the older islands (especially Lanzarote and Fuerteventura). There was no relationship between time alone and species richness for the Azores or Macaronesia as a whole (Fig. 2; Tables 2 \& 4). Elevation had a positive relationship with indigenous species richness in Macaronesia (Fig. 2). Distance to mainland in this region was negatively and significantly related to indigenous species richness (Fig. 2). Distance to the closest island, or to an older island, was never related to species richness $\left(r^{2}<0.09 ; P>0.05\right.$ in all cases).

The different GDM formulations seemed to improve the area model for the Azores only slightly, if at all. Moreover, this was only when including age as a linear positive function with richness (Table 2). The number of Azorean endemics was, however, most strongly correlated with the model combining area and the proportion of natural forest cover per island (ApN; Table 2). Endemic and indigenous species richness was positively correlated with both factors. For the Canary Islands, the hump-shaped relationship between richness of all species groups and time was reflected in the most parsimonious model being the $\mathrm{ATT}^{2}$ in every case (Table 3 ). In fact, adding age to most of the area
Azores
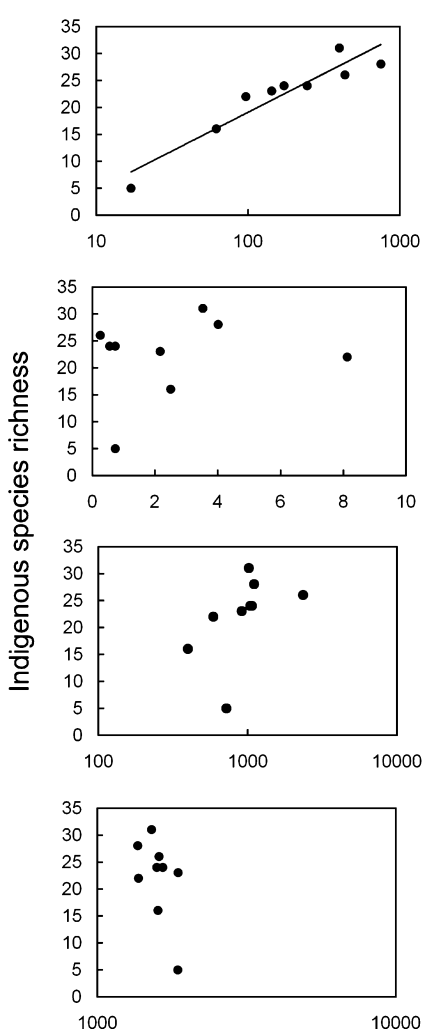

Canary Islands
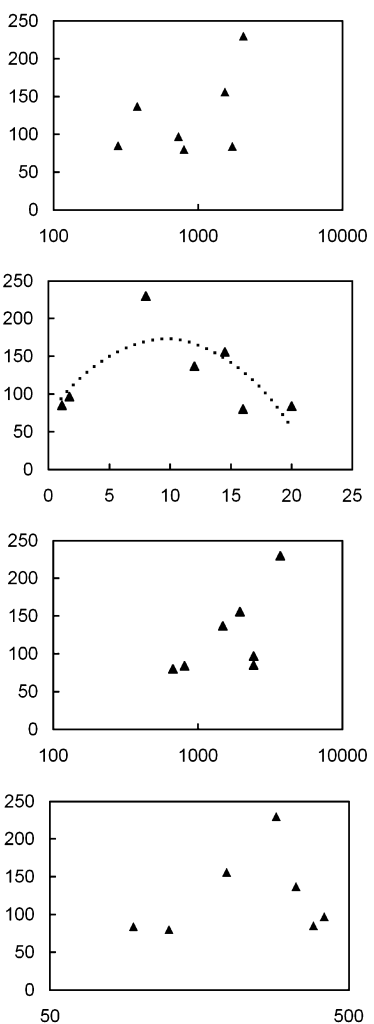

Macaronesia

-Azores - Madeira $\triangle$ Canary Islands
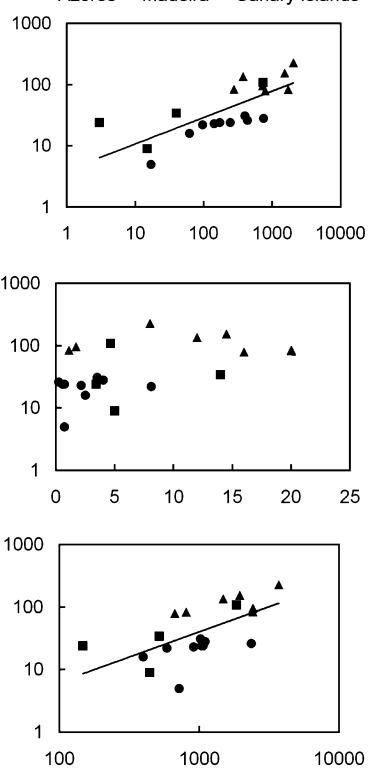

Elevation (m)

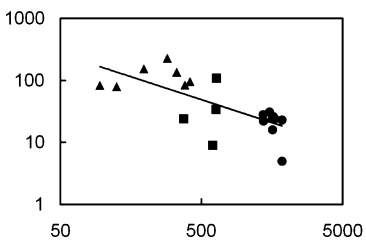

Time (Ma)

Distance to mainland $(\mathrm{km})$

Figure 2 Univariate relationships between different predictors and indigenous spider species richness for the Azores, Canary Islands and Macaronesia as a whole (the curves for single-island endemics and archipelago endemics are mostly similar). Bold lines indicate significant relationships $(P<0.05)$; the dotted line indicates a non-significant trend (as defined by $\left.r^{2}>0.5\right)$. A second-degree polynomial was fitted only for time (as in the $\mathrm{TT}^{2}$ model; see text). 


\section{P. Cardoso et al.}

Table 2 Models for the Azorean spiders (A, log area; T, time; N, log area of natural forest; pN, proportion of area occupied by natural forest; $n=9$ ). The models with $\triangle$ AIC between 0 and 1 are highlighted in bold. The models for single-island endemics are not shown, as only six species are present in the nine islands revealing only non-significant relationships.

\begin{tabular}{|c|c|c|c|c|c|c|}
\hline Model & $F$ & $r^{2}$ & Adj. $r^{2}$ & $\Delta \mathrm{AIC}$ & $P$ & Parameters \\
\hline \multicolumn{7}{|c|}{ Archipelago endemics } \\
\hline A & 28.969 & 0.806 & 0.778 & 3.900 & 0.001 & $-8.296+8.972 \mathrm{~A}$ \\
\hline AT & 12.686 & 0.809 & 0.745 & 5.744 & 0.007 & $-8.073+9.003 \mathrm{~A}-0.116 \mathrm{~T}$ \\
\hline $\mathrm{ATT}^{2}$ & 7.705 & 0.822 & 0.715 & 7.089 & 0.025 & $-8.014+9.333 \mathrm{~A}-0.878 \mathrm{~T}-0.094 \mathrm{~T}^{2}$ \\
\hline $\mathrm{N}$ & 11.971 & 0.631 & 0.578 & 9.957 & 0.011 & $7.031+7.522 \mathrm{~N}$ \\
\hline NT & 5.748 & 0.657 & 0.543 & 10.999 & 0.040 & $6.005+7.853 \mathrm{~N}+0.330 \mathrm{~T}$ \\
\hline $\mathrm{NTT}^{2}$ & 3.776 & 0.694 & 0.510 & 11.980 & 0.093 & $6.798+8.627 \mathrm{~N}-0.942 \mathrm{~T}+0.163 \mathrm{~T}^{2}$ \\
\hline $\mathrm{TT}^{2}$ & 0.056 & 0.018 & - & 20.465 & 0.946 & $10.734+0.828 \mathrm{~T}-0.106 \mathrm{~T}^{2}$ \\
\hline ApN & 26.694 & 0.899 & 0.865 & $\mathbf{0}$ & 0.001 & $-7.858+8.304 \mathrm{~A}+42.426 \mathrm{pN}$ \\
\hline \multicolumn{7}{|c|}{ Indigenous species } \\
\hline A & 54.382 & 0.886 & 0.870 & 0.18 & $<0.001$ & $-9.684+14.370 \mathrm{~A}$ \\
\hline AT & 30.517 & 0.910 & 0.881 & $\mathbf{0}$ & $<0.001$ & $-10.604+14.243 \mathrm{~A}+0.479 \mathrm{~T}$ \\
\hline $\mathrm{ATT}^{2}$ & 16.963 & 0.911 & 0.857 & 1.995 & 0.005 & $-10.599+14.272 \mathrm{~A}+0.412 \mathrm{~T}+0.008 \mathrm{~T}^{2}$ \\
\hline $\mathrm{N}$ & 7.507 & 0.517 & 0.449 & 13.162 & 0.029 & $15.855+10.402 \mathrm{~N}$ \\
\hline NT & 5.620 & 0.652 & 0.536 & 12.221 & 0.042 & $12.293+11.551 \mathrm{~N}+1.145 \mathrm{~T}$ \\
\hline $\mathrm{NTT}^{2}$ & 3.166 & 0.655 & 0.448 & 14.14 & 0.123 & $12.645+11.895 \mathrm{~N}+0.580 \mathrm{~T}+0.072 \mathrm{~T}^{2}$ \\
\hline $\mathrm{TT}^{2}$ & 0.350 & 0.104 & - & 20.729 & 0.718 & $18.072+3.020 \mathrm{~T}-0.298 \mathrm{~T}^{2}$ \\
\hline ApN & 29.918 & 0.907 & 0.877 & 0.2998 & $<0.001$ & $-9.363+13.880 \mathrm{~A}+31.053 \mathrm{pN}$ \\
\hline
\end{tabular}

Table 3 Models for the Canary Islands spiders (A, log area; T, time; $n=7$ ). The models with $\Delta$ AIC between 0 and 1 are highlighted in bold.

\begin{tabular}{|c|c|c|c|c|c|c|}
\hline Model & $F$ & $r^{2}$ & Adj. $r^{2}$ & $\Delta \mathrm{AIC}$ & $P$ & Parameters \\
\hline \multicolumn{7}{|c|}{ Single-island endemics } \\
\hline A & 2.842 & 0.362 & 0.235 & 6.651 & 0.153 & $-116.489+49.629 \mathrm{~A}$ \\
\hline AT & 1.943 & 0.493 & 0.239 & 7.049 & 0.257 & $-152.062+67.535 \mathrm{~A}-1.616 \mathrm{~T}$ \\
\hline ATT $^{2}$ & 6.181 & 0.861 & 0.722 & 0 & 0.084 & $-160.638+62.303 \mathrm{~A}+7.132 \mathrm{~T}-0.439 \mathrm{~T}^{2}$ \\
\hline $\mathrm{TT}^{2}$ & 1.602 & 0.445 & 0.167 & 7.683 & 0.308 & $4.222+9.444 \mathrm{~T}-0.481 \mathrm{~T}^{2}$ \\
\hline \multicolumn{7}{|c|}{ Archipelago endemics } \\
\hline A & 1.663 & 0.250 & 0.100 & 11.482 & 0.254 & $-102.816+58.415 \mathrm{~A}$ \\
\hline AT & 1.151 & 0.365 & 0.048 & 8.457 & 0.403 & $-150.327+82.329 \mathrm{~A}-2.158 \mathrm{~T}$ \\
\hline ATT $^{2}$ & 6.017 & 0.857 & 0.715 & 0 & 0.087 & $-164.395+73.747 \mathrm{~A}+12.191 \mathrm{~T}-0.721 \mathrm{~T}^{2}$ \\
\hline $\mathrm{TT}^{2}$ & 2.626 & 0.568 & 0.351 & 5.769 & 0.187 & $30.749+14.927 \mathrm{~T}-0.770 \mathrm{~T}^{2}$ \\
\hline \multicolumn{7}{|c|}{ Indigenous species } \\
\hline A & 1.564 & 0.238 & 0.086 & 11.074 & 0.266 & $-111.426+80.357 \mathrm{~A}$ \\
\hline AT & 1.163 & 0.368 & 0.052 & 8.485 & 0.400 & $-182.214+115.988 \mathrm{~A}-3.215 \mathrm{~T}$ \\
\hline $\mathrm{ATT}^{2}$ & 6.074 & 0.859 & 0.717 & 0 & 0.086 & $-201.996+103.921 \mathrm{~A}+16.960 \mathrm{~T}-1.013 \mathrm{~T}^{2}$ \\
\hline $\mathrm{TT}^{2}$ & 2.633 & 0.568 & 0.352 & 5.814 & 0.186 & $72.993+20.817 \mathrm{~T}-1.083 \mathrm{~T}^{2}$ \\
\hline
\end{tabular}

models did not improve them, but adding the third parameter, $\mathrm{T}^{2}$, dramatically increased the explanatory power for SIE, endemic and indigenous species (although approaching but not reaching significance, as the number of cases is very low). For all of Macaronesia, the ATT ${ }^{2}$ model seemed to perform best, although all models except the $\mathrm{TT}^{2}$ were always highly significant (Table 4 ).

\section{DISCUSSION}

As one would expect in a region composed of very heterogeneous groups of islands, the spider diversity drivers in Macaronesia are diverse and particular to each archipelago.
In the Azores, area and natural habitat disappearance are the most relevant explanatory variables (the ApN model). In the Canary Islands, a hump-shaped relationship between species richness and time has to be considered in addition to area (i.e. the $\mathrm{ATT}^{2}$ model is best).

\section{Rise and fall of lineages through time in the Canary Islands}

The GDM model predicts that groups occupying oceanic islands speciate due to isolation and increase the species richness of the islands with time. However, oceanic islands, like organisms, may have a limited life span. Both subsidence and 
Table 4 Models for the Macaronesian spiders (A, log area; $\mathrm{T}$, time; $n=20$ ). Models using the logarithms of species richness values as dependent variables were found to have a better fit and are presented. The models with $\triangle$ AIC between 0 and 1 are highlighted in bold.

\begin{tabular}{|c|c|c|c|c|c|c|}
\hline & $F$ & $r^{2}$ & Adj. $r^{2}$ & $\Delta \mathrm{AIC}$ & $P$ & Parameters \\
\hline \multicolumn{7}{|c|}{ Single-island endemics (log) } \\
\hline A & 8.361 & 0.317 & 0.279 & 0.115 & 0.010 & $-0.364+0.463 A$ \\
\hline AT & 6.418 & 0.430 & 0.363 & 0.556 & 0.008 & $-0.356+0.361 \mathrm{~A}+0.037 \mathrm{~T}$ \\
\hline ATT $^{2}$ & 5.304 & 0.499 & 0.405 & 0 & 0.010 & $-0.637+0.396 \mathrm{~A}+0.134 \mathrm{~T}-0.006 \mathrm{~T}^{2}$ \\
\hline $\mathrm{TT}^{2}$ & 3.627 & 0.299 & 0.217 & 4.7 & 0.049 & $0.232+0.126 \mathrm{~T}-0.004 \mathrm{~T}^{2}$ \\
\hline \multicolumn{7}{|c|}{ Archipelago endemics $(\log )$} \\
\hline A & 43.690 & 0.708 & 0.692 & 1.269 & $<0.001$ & $-0.075+0.574 \mathrm{~A}$ \\
\hline AT & 23.265 & 0.732 & 0.701 & 2.43 & $<0.001$ & $-0.072+0.535 \mathrm{~A}+0.014 \mathrm{~T}$ \\
\hline $\mathrm{ATT}^{2}$ & 19.543 & 0.786 & 0.745 & 0 & $<0.001$ & $-0.277+0.560 \mathrm{~A}+0.085 \mathrm{~T}-0.004 \mathrm{~T}^{2}$ \\
\hline $\mathrm{TT}^{2}$ & 2.190 & 0.205 & 0.111 & 24.211 & 0.143 & $0.953+0.074 \mathrm{~T}-0.002 \mathrm{~T}^{2}$ \\
\hline \multicolumn{7}{|c|}{ Indigenous species (log) } \\
\hline A & 23.380 & 0.565 & 0.541 & 0.73 & $<0.001$ & $0.599+0.431 \mathrm{~A}$ \\
\hline AT & 14.402 & 0.629 & 0.585 & 1.041 & $<0.001$ & $0.604+0.378 \mathrm{~A}+0.020 \mathrm{~T}$ \\
\hline $\mathrm{ATT}^{2}$ & 11.386 & 0.681 & 0.621 & $\mathbf{0}$ & $<0.001$ & $0.433+0.399 \mathrm{~A}+0.079 \mathrm{~T}-0.003 \mathrm{~T}^{2}$ \\
\hline $\mathrm{TT}^{2}$ & 3.062 & 0.265 & 0.178 & 14.71 & 0.073 & $1.308+0.071 \mathrm{~T}-0.002 \mathrm{~T}^{2}$ \\
\hline
\end{tabular}

erosion cause a progressive diminishing of area (space) and elevation (habitat), which eventually may drive many of the previously speciated lineages to extinction. According to the GDM, the greatest opportunities for adaptive radiation occur earlier than those for non-adaptive processes linked to withinisland isolation. Biotic interactions within and across trophic levels may be expected to become more important at later stages of the island life cycle, where extinction rate is increasing with the decline of island area. Such biotic/competitive mechanisms may produce species involved in tight mutualisms or it may lead to fine subdivisions of resources, but not at rates sufficient to prevent a decline in the proportion of SIE species (figure 5 in Whittaker et al., 2008; see also Gillespie, 2004). This hump-shaped pattern of species diversity has been reported in several spider genera in the Canary Islands (Fig. 3).

Several spider lineages, of contrasting life styles, have undergone processes of local diversification on the Macaronesian archipelagos (e.g. Oecobius, Walckenaeria, Alopecosa,

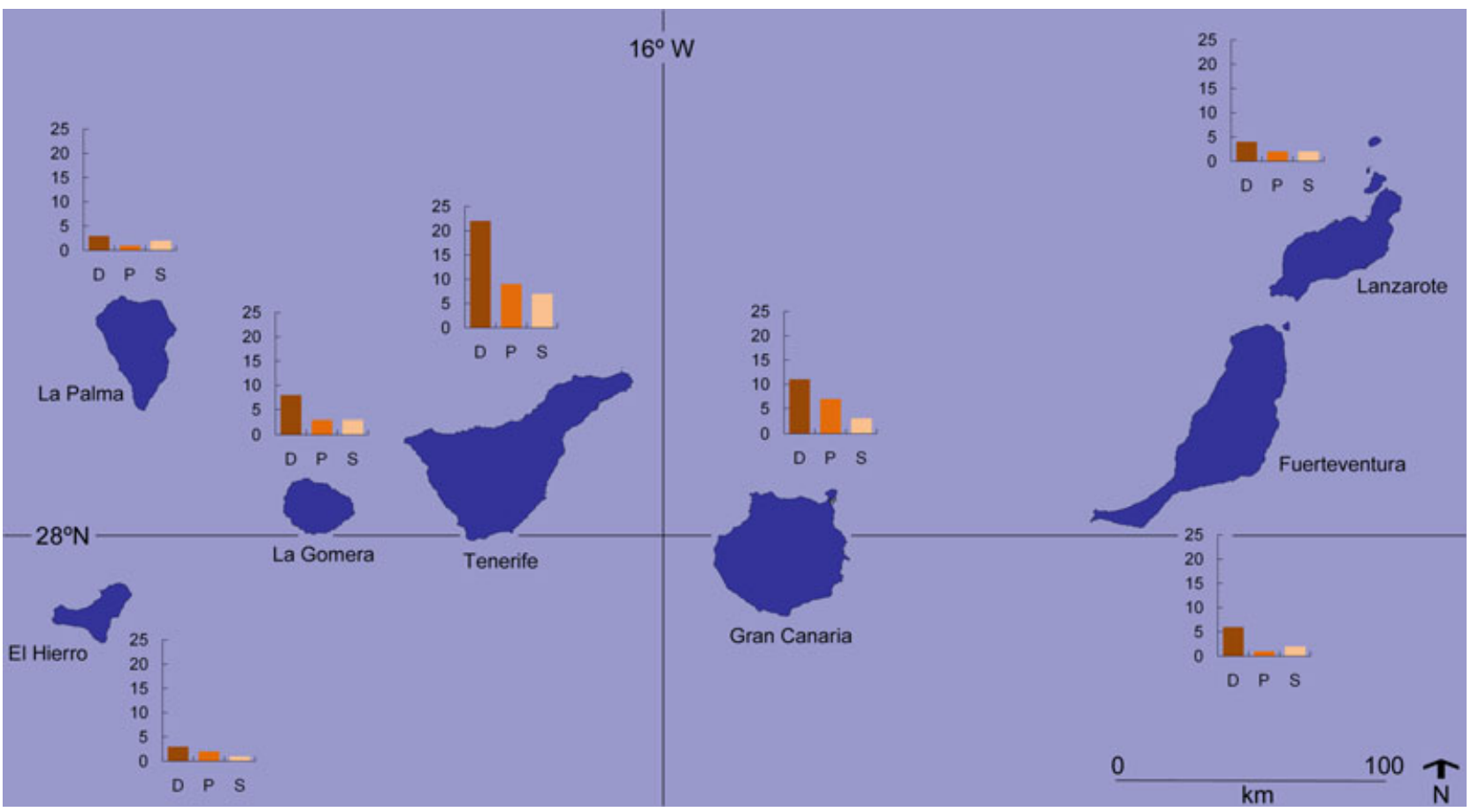

Figure 3 Indigenous species richness of Dysdera (D), Pholcus (P) and Spermophorides (S) for each of the Canary Islands. The western islands, La Palma and El Hierro, are the youngest; the eastern islands, Fuerteventura and Lanzarote, are the oldest (see text for references). 
Hogna and Scotognapha, among others). The woodlousehunter genus Dysdera, and the Pholcidae genera Pholcus and Spermophorides, are by far the best-known examples, thanks to recent taxonomic revisions and phylogenetic analyses (Arnedo et al., 1996, 2000, 2001; Arnedo \& Ribera, 1997, 1999; LópezMercader, 2005; Dimitrov \& Ribera, 2006, 2007; Dimitrov et al., 2008). Although all three genera have endemic species in more than one archipelago, they are particularly diverse in the Canary Islands, where they show the characteristic humpshaped distribution of species diversity across the main islands (Fig. 3). Both tails of the distribution, however, display contrasting patterns of endemism. While species on the youngest islands (La Palma and El Hierro) are, with few exceptions, shared with the nearest older islands, the oldest islands (Fuerteventura and Lanzarote) harbour local endemics. Diversity patterns on the youngest and oldest islands are therefore probably governed by different factors. Maximum likelihood-based analysis of patterns of diversification in the Dysdera species endemic to Lanzarote and Fuerteventura revealed that diversification in this lineage has decelerated through time, which is consistent with an increase in extinction rates due to ecosystem transformation driven by island ageing (Macías-Hernández et al., 2008; Whittaker et al., 2008). Time estimates based on relaxed molecular clocks and external calibration points indicate that deceleration occurred roughly 5-2 Ma. In the case of Pholcus, the curve of species accumulation through time shows clear signs of deceleration 3.5-1 Ma, although this pattern is largely overridden by a subsequent strong acceleration in net speciation rates starting around $0.7 \mathrm{Ma}$, probably driven by sexual selection (Dimitrov et al., 2008).

At this point, it is relevant to state that the general biogeographical patterns differ among the genera mentioned above. Current phylogenetic information on Canarian Dysdera is compatible with the progression rule pattern (Arnedo et al., 2001; Macías-Hernández et al., 2008), while Pholcus and Spermophorides probably colonized Fuerteventura and Lanzarote from the younger Gran Canaria (López-Mercader, 2005; Dimitrov et al., 2008). This observation presents the possibility of an alternative explanation for the origin of the endemics of the oldest islands, which could be the result of secondary replacement of original fauna by new colonists better adapted to increasingly arid conditions. In the specific case of the Canaries, where older islands have shown long-term persistence, loss of old resident species due to aridification and orographic simplification could be compensated by colonization and subsequent diversification of new, better adapted organisms that could take advantage of empty niches and new opportunities. This resilience of older islands biotas is well exemplified by the Selvagens. These islands have gone through different cycles of submersion due to erosion following long periods of volcanic quiescence and eustatic sea-level changes (Geldmacher et al., 2001). In spite of this, they still harbour endemic species. Dysdera and Spermophorides are represented on the Selvagens by SIEs, and in both cases their closest relatives are found in the eastern Canaries.

\section{Explaining differences between archipelagos}

While the best models for the Azores and Canary Islands explain around $90 \%$ of the spider species richness, the Macaronesian models explain between 50 and $80 \%$, with the lowest values referring to SIE richness. This suggests that area and time do not cover all the possible explanatory factors. Carine \& Schaefer (2010) recently proposed the late Quaternary palaeoclimatic variation as an important factor for the low percentage of SIEs in the Azorean flora, compared with the Canary Islands. The climatic stability of the Azores would not allow recent diversification of the Azorean flora. However, phylogenetic data on the Canary Islands spider endemics do not support this hypothesis for this taxon, as the late Quaternary witnessed a deceleration in diversification of the lineages studied (see above).

About $65 \%$ of the surface of the Azorean islands emerged less than $1 \mathrm{Ma}$. This short aerial life span may not have been enough for large local diversification processes to occur (see also Borges \& Brown, 1999). The Canarian islands of El Hierro and La Palma, however, contradict the former suggestion. They emerged only 1.1 and $1.7 \mathrm{Ma}$ (Paris et al., 2005), respectively, yet they harbour roughly double the richness of SIEs, endemic and native species as the entire Azorean archipelago. It has been shown that a few hundred thousand years may be enough for speciation to occur (e.g. cave arthropods in the Azores; see Borges \& Hortal, 2009). The low Azorean richness cannot, therefore, be explained by age alone.

The young age of the Azores may be an explanatory factor for low diversity combined with the large distance that species have to overcome in order to colonize the islands (Borges \& Hortal, 2009). Moreover, the predominant winds and sea currents generally favour a north-to-south colonization. As most long-distance dispersal of spiders is made by ballooning, a passive aerial process, they are mostly dependent on such wind currents. Sea currents, however, may also be important for some non-ballooning taxa. This observation probably explains the presence on Cape Verde of the endemic Dysdera vermicularis, the closest relatives of which are on the Canary Islands $1500 \mathrm{~km}$ to the north (Arnedo et al., 2001). To reach the Azores, a species has to cover a large distance without stepping-stone land masses, and against wind and sea currents. Only species with great dispersal capabilities can overcome these barriers. None of the genera that have undergone diversification in the Canary Islands has endemic species in the Azores (e.g. Dysdera, Oecobius, Pholcus and Spermophorides, all with more than 20 endemic species), although some of them are present in Madeira and the Selvagens, which may reflect the relatively poor dispersal abilities of species of these genera, as they are not known to balloon. Oecobius similis constitutes an exception since it is found in the Azores and is also present on Madeira and the Canary Islands. We suggest that distance dictates that only groups with high dispersal abilities reach the Azores (notably many Linyphiidae), and these expand their range across all the islands, therefore decreasing the proportion of SIEs in the archipelago (Table 1; Borges \& Wunderlich, 
2008). Therefore richness will always be low, since gene flow will prevent population isolation and eventual speciation. On the other hand, if a species is not capable of reaching the Azores, it probably has low dispersal abilities and there is a higher probability of isolation and speciation in other archipelagos. This is apparently supported by the much lower percentages of SIEs in the Azores than in the rest of Macaronesia (Table 1). However, the lower percentage of SIEs in the Azores contradicts the notion that more isolated archipelagos should have higher percentages of endemics.

As seen, the Azores present higher rates of natural habitat disappearance than the other archipelagos, and they also have higher percentages of introduced species of spiders (68\%) than Madeira (32\%) and the Canary Islands (10\%) (Table 1; Oromí et al., 2004; Borges \& Wunderlich, 2005, 2008; Cardoso \& Crespo, 2008). A third possible explanation for the low diversity of spiders in the Azores would be the prevalence of recent unrecorded extinctions. This would be more relevant for endemic species, and it would explain the low richness and low percentage of endemics in the Azores compared with the other archipelagos.

It is probably a combination of the three above-mentioned factors (besides island area), young age, large distance to mainland, and recent human-induced but unrecorded extinctions, which explain the low Azorean richness compared with Madeira, Selvagens or the Canary Islands. How important each individual explanation is remains to be determined.

\section{Unrecorded recent extinctions in the Azores?}

The richness of most Azorean taxa can be explained by a combination of area and time (Borges \& Brown, 1999; Borges et al., 2005; Borges \& Hortal, 2009). However, spiders do not follow this trend, and time seems to play a negligible role, especially for endemic species. The oldest island, Santa Maria (8 Myr old), has few species and no known single-island endemics. This contradicts the patterns exhibited by most other studied taxa (e.g. arthropods in general, beetles and snails), for which Santa Maria hosts the largest number of SIEs (Borges et al., 2005; Borges \& Hortal, 2009). São Miguel, with a complex geological history and topography, also presents a radiation of snail species, although much lower than Santa Maria (Martins, 2005; A.M.F. Martins, unpublished data).

In the Azores, the models that consider the area of natural forest $(\mathrm{N})$ are usually significant, although not as significant as those using the island area (A). This may be due to some native and even endemic species being able to survive in different land-use types from natural forest (Borges \& Wunderlich, 2008; Cardoso et al., 2009). This is the case for the endemic wolf spider Pardosa acoreensis (Lycosidae), which is very abundant in pastures, but is not abundant in natural forests. This is also true for the native money spider Tenuiphantes miguelensis (Linyphiidae), which is particularly abundant in all kinds of forest, including native, mixed exotic and plantation. Using the proportion of natural forest in addition to island area (the ApN model) was the best model for Azorean endemics. As most endemic species are much more adapted to the conditions that existed before human settlement, it is important to consider the extent of deforestation in order to understand fully the richness currently present on each island in an archipelago that has experienced drastic land-use change over the past six centuries (Cardoso et al., 2009). As many native non-endemic species are able to survive in other landuse types besides natural forest, the proportion of natural forest is especially critical for endemic species.

A combination of area and natural habitat loss best explains the observed species richness in the Azores. Santa Maria is one of the most affected islands, enduring extreme deforestation and habitat modification. The second oldest island, São Miguel, has also suffered some of the highest levels of deforestation in the archipelago, and the few forest remnants are extremely disturbed by invasive species such as Pittosporum undulatum and Hedychium gardnerianum (Silva et al., 2008). The larger and most pristine forests are located in Terceira, Flores and Pico: young or intermediate age islands. It is, however, in Pico that an undescribed species of Dysdera is thought to have gone extinct in the past few decades. Three specimens of this species have been found in old collections from the 1950s (M.A. Arnedo, unpublished data). However, all the material of this genus identified from the Azores in the past 10 years belongs to the synanthropic species Dysdera crocata. This invasive species may have caused the extinction of the endemic species through competitive exclusion (Cardoso et al., 2008a).

It was previously suggested that predators are the main trophic group to be negatively influenced by the destruction and disturbance of natural forests in the Azores (Cardoso et al., 2007). As supported by the studies of Davies et al. (2000) and Kimberling et al. (2001), high trophic-level taxa are relatively intolerant of habitat changes, especially those with humanrelated causes (see also Gilbert et al., 1997; Didham et al., 1998). Spiders in particular may be affected by the lack of suitable vegetation for web building (as the native forest was mostly replaced by intensively managed pasture) or adequate prey, although stenophagous spiders are relatively uncommon. As a consequence of both competition and habitat loss and disturbance, many more spider species may have gone extinct without notice on the older islands, even if other groups such as snails and beetles, with a high proportion of herbivores and saprophagous species, have not experienced such large-scale human-induced extinctions (Triantis et al., unpublished data). If this is the case, the positive effect (up to a point) of age on species richness can be offset by a negative effect of human-mediated disturbance on older islands and subsequent undocumented extinctions.

In conclusion, four lines of evidence support the hereby proposed recent extinction hypothesis: (1) the sensitivity of predators to habitat disturbance (Cardoso et al., 2007), (2) the proportion of natural forest area as an important explanatory factor of spider species richness in the Azores (the ApN model), (3) the Azores have a much higher percentage of introduced species than the other archipelagos (Oromí et al., 2004; Borges \& Wunderlich, 2005, 2008; Cardoso \& Crespo, 2008), and (4) despite extremely sparse work before the 1980s, 
one species recently found in old collections but still undescribed is apparently extinct (M.A. Arnedo, unpublished data). Species extinctions of small and under-studied organisms with scarce historical data usually cannot be unambiguously proven. Therefore this hypothesis is supported by a number of mostly indirect pieces of evidence, which should be viewed with caution; however, in view of current knowledge it seems to be the best explanation for the low endemic species richness of the oldest islands.

It is possible that spiders, as the main terrestrial predators in Macaronesia, may act as indicators of future trends in nonpredatory taxa. Taxa that still exhibit high levels of endemism in Santa Maria and São Miguel can actually be 'living dead', just too slow to respond to recent habitat losses. This so-called 'extinction debt' may be paid in the future if immediate actions to restore and expand native forest habitat are not applied (Triantis et al., unpublished data). In many oceanic islands with limited area and high percentages of endemics, extinctions may be playing a critical role in shaping the current diversity (Steadman, 2006). Whether such extinctions have already occurred or will occur in the future may depend on the organisms and how fast they respond to change, but spiders seem to be an obvious candidate indicator group. Such concerns and uncertainties should always be present for both conservationists and biogeographers working in these regions.

\section{ACKNOWLEDGEMENTS}

We thank Lawrence Heaney, Robert Whittaker and Gustavo Hormiga for useful suggestions concerning previous versions of the manuscript. António de Frias Martins disclosed a great deal of interesting data regarding a number of new species of snails in São Miguel. P.C. and K.A.T. were supported by Fundação para a Ciência e Tecnologia (SFRH/BPD/40688/2007 and SFRH/BPD/44306/2008, respectively). Further funding support was provided by an ICREA Academia award for excellence in research from the Generalitat de Catalunya to M.A. P.B. has been funded for several years by a science management grant from CITA-A, and recently under the DRCT projects M2.1.2/I/017/2007 and M.2.1.2/I/003/2008, and the EU projects INTERREGIII B 'ATLÂNTICO' (20042006) and BIONATURA (2006-2008).

\section{REFERENCES}

Arnedo, M.A. \& Ribera, C. (1997) Radiation of the genus Dysdera (Araneae, Haplogynae, Dysderidae) in the Canary Islands: the island of Gran Canaria. Zoologica Scripta, 26, 205-243.

Arnedo, M.A. \& Ribera, C. (1999) Radiation of the genus Dysdera (Araneae, Dysderidae) in the Canary Islands: the island of Tenerife. Journal of Arachnology, 27, 604-662.

Arnedo, M.A., Oromí, P. \& Ribera, C. (1996) Radiation of the genus Dysdera (Araneae, Haplogynae, Dysderidae) in the Canary Islands: the Western islands. Zoologica Scripta, 25, 241-274.
Arnedo, M.A., Oromí, P. \& Ribera, C. (2000) Systematics of the genus Dysdera (Araneae, Dysderidae) in the Eastern Canaries. Journal of Arachnology, 28, 261-292.

Arnedo, M.A., Oromí, P. \& Ribera, C. (2001) Radiation of the spider genus Dysdera (Araneae, Dysderidae) in the Canary Islands: cladistic assessment based on multiple data sets. Cladistics, 17, 313-353.

Borges, P.A.V. \& Brown, V.K. (1999) Effect of island geological age on the arthropod species richness of Azorean pastures. Biological Journal of the Linnean Society, 66, 373-410.

Borges, P.A.V. \& Brown, V.K. (2004) Arthropod community structure in pastures of an island archipelago (Azores): looking for local-regional species richness patterns at smallscales. Bulletin of Entomological Research, 94, 111-121.

Borges, P.A.V. \& Hortal, J. (2009) Time, area and isolation: factors driving the diversification of Azorean arthropods. Journal of Biogeography, 36, 178-191.

Borges, P.A.V. \& Wunderlich, J. (2005) Araneae. A list of the terrestrial fauna (Mollusca and Arthropoda) and flora (Bryophyta, Pteridophyta and Spermatophyta) from the Azores (ed. by P.A.V. Borges, R. Cunha, R. Gabriel, A.M.F. Martins, L. Silva and V. Vieira), pp. 178-180. Direcção Regional de Ambiente and Universidade dos Açores, Horta, Angra do Heroísmo and Ponta Delgada.

Borges, P.A.V. \& Wunderlich, J. (2008) Spider biodiversity patterns and their conservation in the Azorean archipelago, with description of new taxa. Systematics and Biodiversity, 6, 249-282.

Borges, P.A.V., Cunha, R., Gabriel, R., Martins, A.M.F., Silva, L., Vieira, V., Dinis, F., Lourenço, P. \& Pinto, N. (2005) Description of the terrestrial Azorean biodiversity. A list of the terrestrial fauna (Mollusca and Arthropoda) and flora (Bryophyta, Pteridophyta and Spermatophyta) from the Azores (ed. by P.A.V. Borges, R. Cunha, R. Gabriel, A.M.F. Martins, L. Silva and V. Vieira), pp. 21-68. Direcção Regional de Ambiente and Universidade dos Açores, Horta, Angra do Heroísmo and Ponta Delgada.

Cardoso, P. \& Crespo, L. (2008) Araneae. A list of the terrestrial fungi, flora and fauna of Madeira and Selvagens archipelagos (ed. by P.A.V. Borges, C. Abreu, A.M.F. Aguiar, P. Carvalho, R. Jardim, I. Melo, P. Oliveira, C. Sérgio, A.R.M. Serrano and P. Vieira), pp. 283-286. Direcção Regional do Ambiente da Madeira and Universidade dos Açores, Funchal and Angra do Heroísmo.

Cardoso, P., Borges, P.A.V. \& Gaspar, C. (2007) Biotic integrity of the arthropod communities in the natural forests of Azores. Biodiversity and Conservation, 16, 2883-2901.

Cardoso, P., Borges, P.A.V. \& Macías-Hernández, N. (2008a) Dysdera crocata C.L. Koch, 1838. Invasive terrestrial flora and fauna of Macaronesia. Top 100 in Azores, Madeira and Canaries (ed. by L. Silva, E.L. Ojeda and J.L. RodriguezLuengo), pp. 415-417. ARENA, Ponta Delgada.

Cardoso, P., Gaspar, C., Pereira, L.C., Silva, I., Henriques, S.S., Silva, R.R. \& Sousa, P. (2008b) Assessing spider species richness and composition in Mediterranean cork oak forests. Acta Oecologica, 33, 114-127. 
Cardoso, P., Scharff, N., Gaspar, C., Henriques, S.S., Carvalho, R., Castro, P.H., Schmidt, J.B., Silva, I., Szüts, T., Castro, A. \& Crespo, L.C. (2008c) Rapid biodiversity assessment of spiders (Araneae) using semi-quantitative sampling: a case study in a Mediterranean forest. Insect Conservation and Diversity, 1, 71-84.

Cardoso, P., Aranda, S.C., Lobo, J.M., Dinis, F., Gaspar, C. \& Borges, P.A.V. (2009) A spatial scale assessment of habitat effects on arthropod communities of an oceanic island. Acta Oecologica, 35, 590-597.

Carine, M.A. \& Schaefer, H. (2010) The Azores diversity enigma: why are there so few Azorean endemic flowering plants and why are they so widespread? Journal of Biogeography, 37, 77-89.

Carracedo, J.C., Singer, B., Jicha, B., Guillou, H., Rodríguez, E., Badiola, E.R., Meco, J., Pérez Torrado, F.J., Gimeno, D., Socorro, S. \& Láinez, A. (2003) La erupción y el tubo volcánico del Volcán Corona (Lanzarote, Islas Canarias). Estudios Geológicos, 59, 277-302.

Crespo, L.C., Cardoso, P., Silva, I. \& Menezes, D. (2009a) Spiders (Arachnida: Araneae) from the Selvagens Islands (Portugal): additions to the current knowledge. Boletin de la Sociedad Entomologica Aragonesa, 45, 343-348.

Crespo, L.C., Cardoso, P., Henriques, S.S \& Gaspar, C. (2009b) Spiders (Araneae) from Porto Santo (Portugal, Madeira): additions to the current knowledge. Boletin de la Sociedad Entomologica Aragonesa, 45, 471-475.

Davies, K.F., Margules, C.R. \& Lawrence, J.F. (2000) Which traits of species predict population declines in experimental forest fragments? Ecology, 81, 1450-1461.

Didham, R.K., Lawton, J.H., Hammond, P.M. \& Eggleton, P. (1998) Trophic structure stability and extinction dynamics of beetles (Coleoptera) in tropical forest fragments. Philosophical Transactions of the Royal Society B: Biological Sciences, 353, 437-451.

Dimitrov, D. \& Ribera, C. (2006) Three new species of Pholcus (Araneae, Pholcidae) from the Canary Islands with notes on the genus Pholcus in the archipelago. Journal of Arachnology, 34, 126-134.

Dimitrov, D. \& Ribera, C. (2007) The genus Pholcus (Araneae, Pholcidae) in the Canary Islands. Zoological Journal of the Linnean Society, 151, 59-114.

Dimitrov, D., Arnedo, M.A. \& Ribera, C. (2008) Colonization and diversification of the spider genus Pholcus Walckenaer, 1805 (Araneae, Pholcidae) in the Macaronesian archipelagos: evidence for long-term occupancy yet rapid recent speciation. Molecular Phylogenetics and Evolution, 48, 596614.

Emerson, B.C. \& Gillespie, R.G. (2008) Phylogenetic analysis of community assembly and structure over space and time. Trends in Ecology and Evolution, 23, 619-630.

Fattorini, S. (2009) On the general dynamic model of oceanic island biogeography. Journal of Biogeography, 36, 1100-1110.

Fernández-Palacios, J.M., Arévalo, J.R., Delgado, J.D. \& Otto, R. (2004) Canarias: ecología, medio ambiente y desarrollo. Centro de la Cultura Popular de Canarias, La Laguna.
Funk, V.A. \& Wagner, W.L. (1995) Biogeographic patterns in the Hawaiian Islands. Hawaiian biogeography: evolution on a hot spot archipelago (ed. by W.L. Wagner and V.L. Funk), pp. 379-419. Smithsonian Institution, Washington, DC.

García, L.V. (2004) Escaping the Bonferroni iron claw in ecological studies. Oikos, 105, 657-663.

Gaspar, C., Borges, P.A.V. \& Gaston, K.J. (2008) Diversity and distribution of arthropods in natural forests of the Azores archipelago. Arquipélago. Life and Marine Sciences, 25, 1-30.

Geldmacher, J., Hoernle, K., van den Bogaard, P., Zankl, G. \& Garbe-Schonberg, D. (2001) Earlier history of the $\geq 70$-Maold Canary hotspot based on the temporal and geochemical evolution of the Selvagen Archipelago and neighboring seamounts in the eastern North Atlantic. Journal of Volcanology and Geothermal Research, 111, 55-87.

Geldmacher, J., Hoernle, K., Bogaard, P.V.D., Duggen, S. \& Werner, R. (2005) New ${ }^{40} \mathrm{Ar} /{ }^{39} \mathrm{Ar}$ age and geochemical data from seamounts in the Canary and Madeira volcanic province: support for the mantle plume hypothesis. Earth and Planetary Science Letters, 237, 85-101.

Gilbert, F., Gonzalez, A. \& Evans-Freke, I. (1997) Corridors maintain species richness in the fragmented landscapes of a microecosystem. Philosophical Transactions of the Royal Society B: Biological Sciences, 265, 577-582.

Gillespie, R.G. (2004) Community assembly through adaptive radiation in Hawaiian spiders. Science, 303, 356-359.

Gillespie, R.G. \& Roderick, G.K. (2002) Arthropods on islands: colonization, speciation, and conservation. Annual Review of Entomology, 47, 595-632.

Hormiga, G., Arnedo, M.A. \& Gillespie, R.G. (2003) Speciation on a conveyor belt: sequential colonization of the Hawaiian Islands by Orsonwelles spiders (Araneae: Linyphiidae). Systematic Biology, 52, 70-88.

Juan, C., Emerson, B.C., Oromí, P. \& Hewitt, G.M. (2000) Colonization and diversification: towards a phylogeographic synthesis for the Canary Islands. Trends in Ecology and Evolution, 15, 104-109.

Kalmar, A. \& Currie, D.J. (2006) A global model of island biogeography. Global Ecology and Biogeography, 15, 72-81.

Kimberling, D.N., Karr, J.R. \& Fore, L.S. (2001) Measuring human disturbance using terrestrial invertebrates in the shrub-steppe of eastern Washington (USA). Ecological Indicators, 1, 63-81.

Kreft, H., Jetz, W., Mutke, J., Kier, G. \& Barthlott, W. (2008) Global diversity of island floras from a macroecological perspective. Ecology Letters, 11, 116-127.

López-Mercader, N. (2005) Evolutionary processes of the genus Spermophorides (Araneae, Pholcidae) in the Canary Islands. Departamento de Biología Animal, Universitat de Barcelona, Barcelona.

Losos, J.B. \& Ricklefs, R.E. (2009) Adaptation and diversification on islands. Nature, 457, 830-836.

MacArthur, R.H. \& Wilson, E.O. (1963) An equilibrium theory of insular zoogeography. Evolution, 17, 373-387.

MacArthur, R.H. \& Wilson, E.O. (1967) The theory of island biogeography. Princeton University Press, Princeton, NJ. 
Macías-Hernández, N., Oromí, P. \& Arnedo, M.A. (2008) Patterns of diversification on old volcanic islands as revealed by the woodlouse-hunter spider genus Dysdera (Araneae, Dysderidae) in the eastern Canary Islands. Biological Journal of the Linnean Society, 94, 589-615.

Martins, A.M.F. (1993) The Azores - westernmost Europe: where evolution can be caught red-handed. Boletim do Museu Municipal do Funchal, S2, 181-198.

Martins, A.M.F. (2005) The shaping of a species: the Azorian Drouetia Gude (Pulmonata: Zonitidae: Oxychilus) as a model. Records of the Western Australian Museum, Supplement, 668, 143-157.

Moran, M.D. (2003) Arguments for rejecting the sequential Bonferroni in ecological studies. Oikos, 100, 403-405.

Myers, N., Mittermeier, R.A., Mittermeier, C.G., Fonseca, G.A.B. \& Kent, J. (2000) Biodiversity hotspots for conservation priorities. Nature, 403, 853-858.

Nunes, J.C. (1999) A actividade vulcânica na ilha do Pico do Plistocénico Superior ao Holocénico: mecanismo eruptivo e hazard vulcânico. PhD Thesis, Universidade dos Açores, Ponta Delgada.

Oromí, P., García, A. \& Macías, N.E. (2004) Araneae. Lista de especies silvestres de Canarias (hongos, plantas y animales terrestres) (ed. by I. Izquierdo, J.L. Martín, N. Zurita and M. Arechavaleta), pp. 164-172. Consejería de Medio Ambiente y Ordenación Territorial, Gobierno de Canarias, Tenerife.

Parent, C.E. \& Crespi, B.J. (2006) Sequential colonization and diversification of Galapagos endemic land snail genus Bulimulus (Gastropoda, Stylommatophora). Evolution, 60, 2311-2328.

Paris, R., Guillou, H., Carracedo, J.C. \& Perez Torrado, F.J. (2005) Volcanic and morphological evolution of La Gomera (Canary Islands), based on new K-Ar ages and magnetic stratigraphy: implications for oceanic island evolution. Journal of the Geological Society, 162, 501-512.

Peck, S.B. \& Kukalova-Peck, J. (1990) Origin and biogeography of the beetles (Coleoptera) of the Galápagos Archipelago, Ecuador. Canadian Journal of Zoology, 68, 1617-1638.

Peck, S.B., Wigfull, P. \& Nishida, G. (1999) Physical correlates of insular species diversity: the insects of the Hawaiian Islands. Annals of the Entomological Society of America, 92, 529-536.

Platnick, N.I. (2009) The world spider catalog, version 9.5. American Museum of Natural History, New York. Available at: http://research.amnh.org/entomology/spiders/catalog/ index.html (accessed 20 May 2009).

Price, J.P. \& Clague, D.A. (2002) How old is the Hawaiian biota? Geology and phylogeny suggest recent divergence. Proceedings of the Royal Society B: Biological Sciences, 269, 2429-2435.

Rosenzweig, M.L. (1995) Species diversity in space and time. Cambridge University Press, Cambridge.

Silva, L., Ojeda, E.L. \& Rodríguez-Luengo, J.L. (eds) (2008) Invasive terrestrial flora and fauna of Macaronesia. Top 100 in Azores, Madeira and Canaries. ARENA, Ponta Delgada.

Silveira, L.M.A. (2007) Learning with history: interaction with nature during the human colonization in Terceira Island. MSc Thesis, University of Azores, Angra do Heroísmo.
Steadman, D.W. (2006) Extinction and biogeography of tropical Pacific birds. University of Chicago Press, Chicago.

Triantis, K.A., Mylonas, M. \& Whittaker, R.J. (2008a) Evolutionary species-area curves as revealed by single-island endemics: insights for the inter-provincial species-area relationship. Ecography, 31, 401-407.

Triantis, K.A., Nogués-Bravo, D., Hortal, J., Borges, P.A.V., Adsersen, H., Fernández-Palacios, M., Araújo, M.B. \& Whittaker, R.J. (2008b) Measurements of area and the (island) species-area relationship: new directions for an old pattern. Oikos, 117, 1555-1559.

Whittaker, R.J. (2006) Island species-energy theory. Journal of Biogeography, 33, 11-12.

Whittaker, R.J. \& Fernández-Palacios, J.M. (2007) Island biogeography: ecology, evolution, and conservation, 2nd edn. Oxford University Press, Oxford.

Whittaker, R.J., Triantis, K.A. \& Ladle, R.J. (2008) A general dynamic theory of oceanic island biogeography. Journal of Biogeography, 35, 977-994.

Whittaker, R.J., Triantis, K.A. \& Ladle, R.J. (2010) A general dynamic theory of oceanic island biogeography: extending the MacArthur-Wilson theory to accommodate the rise and fall of volcanic islands. The theory of island biogeography revisited (ed. by J.B. Losos and R.E. Ricklefs), pp. 88-115. Princeton University Press, Princeton, NJ.

Wilson, E.O. (1969) The species equilibrium. Brookhaven Symposium of Biology, 22, 38-47.

Wright, D.H. (1983) Species-energy theory: an extension of species-area theory. Oikos, 41, 496-506.

\section{BIOSKETCH}

Pedro Cardoso is currently a postdoc at the Smithsonian Institution and the University of Azores. His research interests comprise biodiversity assessment and monitoring, prioritization of areas and species for conservation, ecological modelling, island biogeography, subterranean biology and spider taxonomy.

Author contributions: All authors conceived the ideas; P.C., M.A.A. and P.A.V.B. collected the data; P.C. and K.A.T. analysed the data; and P.C. and M.A.A. led the writing.

Editor: Lawrence Heaney

This paper is an additional contribution to the Special Issue that arose from the symposium Evolutionary islands: 150 years after Darwin (http://science.naturalis.nl/darwin2009), held from 11 to 13 February 2009 at the Museum Naturalis, Leiden, The Netherlands. The theme of the symposium was to explore the contribution of islands to our understanding of evolutionary biology and to analyse the role of island biological processes in a world in which the insularity of island and mainland ecosystems is being drastically altered. 